\title{
Biberiye Ekstraktlarının Buğday Çimlenmesi ve Tahıl Depo Zararlıları Üzerine Etkileri
}

\author{
Cennet YAMAN ${ }^{\mathscr{q}}$, Şeyda ŞİMŞEK ${ }^{2}$ \\ ${ }^{1}$ Bozok Ünv., Ziraat Fakültesi, Tarla Bitkileri Bölümü Yozgat, ${ }^{2}$ Bozok Ünv., Ziraat Fakültesi, Bitki Koruma Bölümü Yozgat \\ ${ }^{1}$ https://orcid.org/0000-0002-2364-8171, ${ }^{2}$ https://orcid.org/0000-0002-0096-8949 \\ 凶: cennet.yaman@bozok.edu.tr
}

\section{ÖZET}

$\mathrm{Bu}$ çalışmada, biberiye (Rosmarinus officinalis L.) ekstraktlarının depolanmış önemli bir tahıl olan buğday (Triticum aestivum L.) tohumlarının çimlenmesi üzerindeki fitotoksik etkisi ve tahıl zararlıları olan Sitophilus oryzae (L.) ve Rhyzopertha dominica (F.) türleri üzerindeki insektisidal aktiviteleri araştırılmıştır. Biberiye bitkisinin yaprak kısımlarından ekstrakt elde edilmesi için farklı çözücüler (etanol, metanol ve aseton) kullanılmış ve en yüksek ekstrakt verimi \%10.5 ile aseton çözücüsünden elde edilmiştir. Aseton ekstraktının $250 \mu \mathrm{g} / \mathrm{ml}\left(\mathrm{A}_{250}\right)$ ve $500\left(\mathrm{~A}_{500}\right) \mu \mathrm{g} / \mathrm{ml}$ konsantrasyonları buğday tohumlarının çimlenmesinde en yüksek değere (sirasiyla \%96.7 ve \%95.6) sahip olurken, kontrol (\%98.9) uygulamaları ile aralarında istatistiki fark olmadığı tespit edilmiştir. Hatta $A_{250}$ ekstrakt1 $(85 \pm 0.6 \mathrm{mg})$ ile kontrol1 $(92 \pm 0.6 \mathrm{mg})$ uygulamalarında istatistiki olarak en yüksek bitki taze ağırlığg saptanmıştır. Tüm ekstraktlar buğday bitkisinin radikula ve plumula uzunlukları üzerinde negatif etkiye sahip olmuştur. Biberiye ekstraktlarının artan konsantrasyonları tüm parametrelerde negatif etkiyi artırmıştır. Ayrıca ekstrakların depo tahıl zararlısı türler üzerindeki insektisidal etkisi incelendiğinde, 72 saat sonunda en yüksek değer $R$. dominca için aseton ekstrakında (\%68.33), S. oryzae için ise etanol ekstrakında (\%58.33) bulunmuştur. Sonuç olarak, biberiye ekstraklarının depolanmış tahıl zararlılarının mücadelesinde kullanılabileceği tartışılmıştır.

\section{Araștırma Makalesi}

\section{Makale Tarihçesi}

Geliş Tarihi : 03.04.2019

Kabul Tarihi : 11.09 .2019

\section{Anahtar Kelimeler}

Rosmarinus officinal

Sitophilus oryzae

Rhyzopertha dominica

Fitotoksisite

Buğday

\section{The Effects of Rosemary Extracts on Wheat Germination and Grain Storage Pests}

\section{ABSTRACT}

In this study, the phytotoxic effects of rosemary (Rosmarinus officinalis L.) extracts on the germination of wheat (Triticum aestivum L.) and insecticidal effects on the Rhyzopertha dominica (F.) and Sitophilus oryzae (L.) species were investigated. Different solvents (ethanol, methanol and acetone) were used to obtain extract from leaves of rosemary, and the highest extract yield was obtained from acetone solvent with $10.5 \%$. The $250 \mu \mathrm{g} / \mathrm{ml}\left(\mathrm{A}_{250}\right)$ and $500\left(\mathrm{~A}_{500}\right) \mu \mathrm{g} / \mathrm{ml}$ concentrations of acetone extract sustained the highest seed germination of wheat as $96.7 \%$ and $95.6 \%$, respectively, and there was no statistical difference between the controls (98.9\%). In addition, control1 $(92 \pm 0.6 \mathrm{mg})$ and $A_{250}$ extract $(85 \pm 0.6 \mathrm{mg})$ resulted in the highest fresh weight of wheat statistically. All the extracts had a negative effect on the radicula and plumula length of wheat. Moreover, as efficacy of the extracts on stored grain pests was examined, after 72 hours exposure. The highest mortality was found as $68.33 \%$ in acetone extract for $R$. dominca, whereas this ratio was $58.33 \%$ in ethanol extract for $S$. oryzae. In conclusion, it was seen that rosemary extracts can be used in controlling the pests of stored grains.

\section{Research Article}

$\begin{array}{ll}\text { Article History } & \\ \text { Received } & : 03.04 .2019 \\ \text { Accepted } & : 11.09 .2019\end{array}$

\section{Keywords}

Rosmarinus officinal

Sitophilus oryzae

Rhyzopertha dominica

Phytotoxicity

Wheat 


\section{GİRIŞ}

Buğdaygiller (Poaceae) familyasının üyesi olan buğday (Triticum aestivum L.), kültür bitkileri içerisinde insan beslenmesinde yer alan, dünyada ekiliş alanı ve üretimi bakımından önemli bir yere sahip olan bir bitkidir. Göstermiş olduğu varyasyondan dolayı dünya genelinde yaygın olarak tarımı yapılan buğday, birçok ülkede insanların temel ihtiyaç maddelerinden biridir. Dünyada 2017 yılında 218.5 milyon hektar alanda 771.71 milyon ton buğday üretimi gerçekleşmiş olup, Türkiye'de ise 7.6 milyon hektar alanda ve 21.5 milyon ton üretim elde edilmiştir (FAO, 2019).

Tahılların üretiminden tüketimine kadar meydana gelen tüm kayıplar yetiştirme, hasat, depolama, işleme ve tüketim aşamalarında meydana gelmektedir. Bunlar içerisinde ise depodaki kayıplar önemli bir yer tutmaktadır. Bu aşamada depo zararlıları önemli oranda ürün kaybına sebebiyet vermektedir (Kumar ve Kalita, 2017). Depolama döneminde böcek zararlıları tahıllara hem niteliksel hem de niceliksel olarak zarar vermekte, bu da tohum, yiyecek veya yem için uygun olmamalarına sebep olmaktadır. Ayrıca, gıda kontaminasyonu nedeniyle gida endüstrisi için ciddi problemler oluşturmaktadır (Rajendran, 2002). Sitophilus oryzae (L.) (Coleoptera: Curculionidae) ve Rhyzopertha dominica(F.) (Coleoptera: Bostrychidae) tahıl depolarında rastlanan en önemli böcek zararlıları arasındadır (Hardman, 1978).

Depolanmış tahıl zararlılarının etkin kontrolü için sentetik kimyasal pestisitler aktif olarak yıllardır kullanılmaktadır. Fakat sentetik kimyasalların memeliler için potansiyel risk oluşturması, işlenmiş ürünlerdeki kimyasal kalıntılarının tüketiciler için endişe oluşturması, böcek popülasyonlarında kimyasallara karşı dayanıklılık oluşması, ekolojik dengenin değişmesi, kimyasal maliyetlerinin artışı gibi sebeplerden dolayı bilim adamları depolanmış ürün zararlılarınakarşı mücadele için yeni ve doğal ürünler araştırmaya başlamıştır (Aslam ve ark., 2002; Salem ve ark., 2007; Mahdian ve Rahman, 2008). Günümüzde kimyasal böcek ilaçlarına karşı güvenli alternatiflerin kullanılmasına duyulan büyük ihtiyaç, dünyanın pek çok yerinde güçlü bir şekilde savunulmaktadır. Öncelikle çevreye ve insan sağlığına daha az zararlı ve ucuz organik kaynaklar araştırılmak istenmiştir. Özellikle son zamanlarda birçok biyolojik aktivitesi olduğu bilinen tıbbi bitkilerin insektisidal, herbisidal vb. aktivitelerine yönelik birçok araştırma yapılmış ve yapılmaktadır (Guru-Pirasanna-Pandi ve ark., 2018; Chen ve ark., 2018; Trivedi ve ark., 2018; Ito ve ark., 2018; Khan ve ark., 2019). Tıbbi bitkiler doğal ürün olmalarından dolayı daha güvenli tarım ürünleri için zemin hazırlamakta ve daha az kirliliğe neden olmaktadır (Sodaeizadeh ve ark., 2010).
Tıbbi ve aromatik bitkiler grubunda yer alan ve birçok biyolojik aktiviteye sahip olan biberiye (Rosmarinus officinalis L.; Lamiaceae familyası), tipik olarak Akdeniz bölgesinde bulunan çok yıllık bir bitkidir (Alipour ve Saharkhiz, 2016). Antioksidan aktivitesinin yüksek olması ve geleneksel tıpta kullanılmasından dolayı insan sağlığı için şifalı bir bitki olarak bilinmektedir (Vicente ve ark., 2013; Rajendran ve ark., 2014; Ablat ve ark., 2016; Yeddes ve ark., 2018). Ayrica biberiye ekstraktının antibakteriyel (Amaral ve ark., 2018; Keikhaie ve ark., 2018), antifungal (Ksouri ver ark., 2017; Sepehri ve ark., 2016) ve insektisidal (Isman ve ark., 2008; Pavela, 2006; Papachristos ve ark., 2004) gibi aktivitelere sahip olduğunu gösteren çeşitli çalışmalar bulunmaktadır.

$\mathrm{Bu}$ nedenle bu çalışmada, insan sağlığına zararlı olmayan doğal bir insektisit elde edebilmek amacıyla, biberiye ekstraktlarının tahıl zararlısı olan Sitophilus oryzae (L.) ve Rhyzopertha dominica (F.) türleri üzerine insektisit etkisi ile önemli bir tahıl olan buğday tohumlarının çimlenmeleri üzerine fitotoksik etkileri incelenmiştir.

\section{MATERYAL ve METOD}

\section{Materyal}

$\mathrm{Bu}$ çalışmada Bozok Üniversitesi Ziraat Fakültesi Tarla Bitkileri Bölümünden ekmeklik buğday (Triticum aestivum L.) tohumları (Tosun bey, 2017) ve Atatürk Bahçe Kültürleri Merkez Araştırma Enstitüsünden $\left(40^{\circ} 39^{\prime} 32 \mathrm{~N}, 2^{\circ} 16^{\prime} 55 \mathrm{E}, 6 \mathrm{~m}\right)$ kültür olarak yetiştirilen ve ikinci yılında hasat edilen biberiye (Rosmarinus officinalis) bitkisinin yaprak kısımları kullanılmıştır. Çalışmada kullanılan böcekler (Sitophilus oryzae ve Rhyzopertha dominica) Ankara Zirai Araştırma Enstitüsünden alınarak Yozgat Bozok Üniversitesi Ziraat Fakültesi Bitki Koruma Bölümü'nde stok kültürü oluşturulmuş ve denemelerde kullanılmıştır.

\section{Ekstraksiyon}

Biberiye bitkisinin yaprak kısımları gölgede kurutulup blenderda (Waring-8011 EB) öğütülmüştür. Elde edilen örneklerden $4 \mathrm{~g}$ tartılıp üzerine $40 \mathrm{ml}$ çözücü (etanol, metanol ve aseton) eklenmiştir. Her örnek için uygulamalar 3 tekrarlı olarak yapılmıştır. Çözeltiler etüvde $40{ }^{\circ} \mathrm{C}$ 'de 1 gün (24 saat) süre ile bekletilmiştir. Elde edilen çözeltiler santrifüj cihazında (Hettich 1401-01) toprak üstü çözeltileri 4.500 rpm'de santrifüj edilmiştir. Süpernatant kısımları alınmış ve evaporatör yardımı ile organik çözücü ayrıştırılmıştır. Elde edilen ekstraktların miktarı belirlenmiş ve $+4{ }^{\circ} \mathrm{C}$ 'de muhafaza edilmiştir. 


\section{Fitotoksik Etki}

Buğday tohumlarının çimlenmesi testi Dikshit ve ark. (1979) tarafından belirtilen metodu modifiye edilerek uygulanmıştır. Ekstraktlardan 250, 500 ve $1000 \mu \mathrm{g} / \mathrm{ml}$ konsantrasyonlarda solüsyonlar hazırlanmıştır. Solüsyonlar A(250, 500, 1000) aseton ekstakları, $\mathrm{E}(250,500,1000)$ etanol ekstakları, $\mathrm{M}(250,500,1000)$ metanol ekstakları olarak ifade edilmiştir. Ayrıca kontrol olarak saf su (Kontrol 1) ve aseton (Kontrol 2) kullanılmıştır. Önceden steril edilmiş $9 \mathrm{~cm}$ çaplarındaki petri kaplarına steril kurutma kağıtları konulmuş ve üzerine \% 15 hipoklorit $(\% 50 \mathrm{NaOCl}$ içeren HES çamaşır suyu) ile steril edilmiş tohumlardan 30 adet yerleştirilmiştir. Her bir petri kabına $5 \mathrm{ml}$ örnek solüsyonlardan eklenmiş ve 48 saat boyunca petri kapları parafinli olarak tutulmuştur. Tohumlar petri kapları içinde kurutma kağıtları arasında 8 saat karanlık, $22 \pm 2{ }^{\circ} \mathrm{C}$ ve 16 saat ışıklı ortamda $\quad 27 \pm 2 \quad{ }^{\circ} \mathrm{C}$ 'de iklim odasında tutularak çimlenmeye bırakılmıştır. Çimlenme oranı 24, 48, 72, 96 ve 120 saat sonunda belirlenmiştir. Kökçük (radikul)'ün 2 mm'lik çıkışı çimlendirme kriteri olarak ele alınmış ve çimlenme oranları (\%) tespit edilmiştir. Ayrıca 6 günün sonunda radikula uzunluğu, plumula uzunluğu ve bitki yaş ağırlığı da ölçülmüsstür. Her bir deneme 3 tekerrürlü olarak yapılmıştır.

\section{Kontak Etki Testi}

Kontak etkinin belirlenmesinde Gökçe ve ark. (2010)'nın kullandığ̣ yöntem takip edilmiştir. Kontak etki denemelerinde, $S$. oryzae ve $R$. dominica erginleri yaş ve cinsiyet gözetmedenher bir petri kabına 10 adet olacak şekilde stok kültürlerinden transfer edilmiştir. Çalışmada metanol, etanol ve asetondan elde edilen ekstraktların \%10'luk ağırlık/hacim (w/v) konsantrasyonları aseton çözücüsü ile hazırlanmıştır. Hazırlanan konsantrasyonlar mikro-aplikatör (Hamilton, Pb-600-1 Repeating Dispenser, $50 \mu \mathrm{l}$ Gastight \& Microliter Syringe), yardımıyla \%10’luk ekstrakt çözeltilerinden her bir böceğe 1 pl topikal olarak böceğin ventral kısmina uygulanmıştır. Kontrolde ise böceklere aynı şekilde aseton uygulaması yapılmıştır. Deneme iki tekrarlı olmak üzere 3 tekerrürlü olarak kurulmuş ve her uygulamada toplamda 60 adet böcek kullanılmış, petri kabı içerisine besin ( $\mathrm{g}$ buğday tanesi) ilave edilerek $27 \pm 2{ }^{\circ} \mathrm{C}$ 'de inkübe edilmiştir. Ölüm sayıları 24 saat arayla 3 gün boyunca kayıt altına alınmıştır.

\section{İstatistik Analizi}

Biberiye ekstraktlarının buğday tohumları üzerine fitotoksik etkileri ve $S$. oryzae ve $R$. dominica erginleri üzerindeki kontak toksisitelerinin belirlenmesi amacıyla elde edilen veriler değerlendirilmiştir. Verilerin yüzde değerleri istatistiki analizden önce arcsin açı değerlerine dönüştürülerek (Snedecor ve Cochran, 1967), varyans analizine (ANOVA) tabi tutulmuş ve ortalamalar arasındaki farklılıklar \%5’lik önem seviyesinde Duncan çoklu karşlaştırma testi ile ortaya konulmuştur (Düzgüneş ve ark., 1983). Kuru 4g biberiye bitkisinden farklı çözücülerden elde edilen ektrakları mg cinsinden hesaplanmış ve aralarındaki farklılık \%5'lik önem seviyesinde Duncan çoklu karşılaştırma testi ile ortaya konulmuştur.

\section{BULGULAR ve TARTIŞMA}

\section{Ekstrakt verimi}

Yapılan çalışma sonucunda biberiye ekstrakt veriminde kullanılan çözücü (metanol, etanol, aseton) türünün etkili olduğu tespit edilmiştir. En yüksek ekstrakt verimi \%10.5 ile aseton çözücüsünden, en düşük ekstrakt ise verimi \%9.1 ile etanolden elde edilmiş ve aralarındaki farkın ( $\mathrm{mg}$ bazında) istatistiksel olarak önemli olduğu saptanmıştır $(p<0.05)$ (Çizelge 1).

Çizelge 1. Biberiye bitkisinin farklı çözücülerdeki ekstrakt verimi

\begin{tabular}{lcc}
\hline \multirow{2}{*}{ Çözücü } & \multicolumn{2}{c}{ Ekstrakt verimi } \\
\cline { 2 - 3 } & Ekstrakt miktarı $(\mathrm{mg}){ }^{1}$ & \% Ekstrakt oranı \\
\hline Aseton & $0.43 \pm 0.01 \mathrm{a}$ & 10.5 \\
Metanol & $0.39 \pm 0.01 \mathrm{ab}$ & 9.6 \\
Etanol & $0.37 \pm 0.02 \mathrm{~b}$ & 9.1 \\
\hline
\end{tabular}

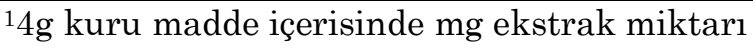

Birçok araştırmacı ekstrakt verimini çözücü, sıcaklık, ekstraksiyon yöntemi, $\mathrm{pH}$ gibi parametrelerinin etkilediğini bildirmiştir (Lu ve ark., 2011; Prasad ve ark., 2012). Rodríguez-Rojo ve ark. (2012) yağı çıkartılmış biberiye yapraklarının etanol ekstrak verimini \%2.4 olarak belirlemiştir. Sánchez-Camargo ve ark. (2014) biberiye yapraklarmdan \%7 etanolde 40 ${ }^{\circ} \mathrm{C}$ ve 150 bar basınçta yüksek ekstrakt verimini \%6.50 olarak tespit etmiştir. Tavassoli ve ark. (2011) biberiye yapraklarından mikrodalga firınında \%60 metanol çözücüsünde $\% 21.5$ ekstrakt verimi elde ettiklerini bildirmişlerdir. Bu çalışmalardan da anlaşlacağı gibi ekstraksiyon yöntemi ve çözücülerin bitki ekstraklarının verimine oldukça ektili olduğu ve nitekim mevcut çalışmada da benzer şekilde çözücünün biberiye bitkisinin ekstrak verimine etki ettiği görülmüsstür.

Biberiye ekstraktlarının buğday çimlenmesi üzerine etkisi

Biberiye bitkisinden farklı çözücü ve farklı konsantrasyonda ekstraktlar hazılanmış ve buğday ( $T$. aestivum L.) tohumlarının çimlenmesi ve fide büyümesi üzerine etkileri incelenmiştir (Çizelge 2). Her bir uygulama için çimlenme yüzdesi beş farklı zamanda değerlendirilmiştir $(48,72,96,120$ ve $144 \mathrm{~s})$ (Şekil 1). 


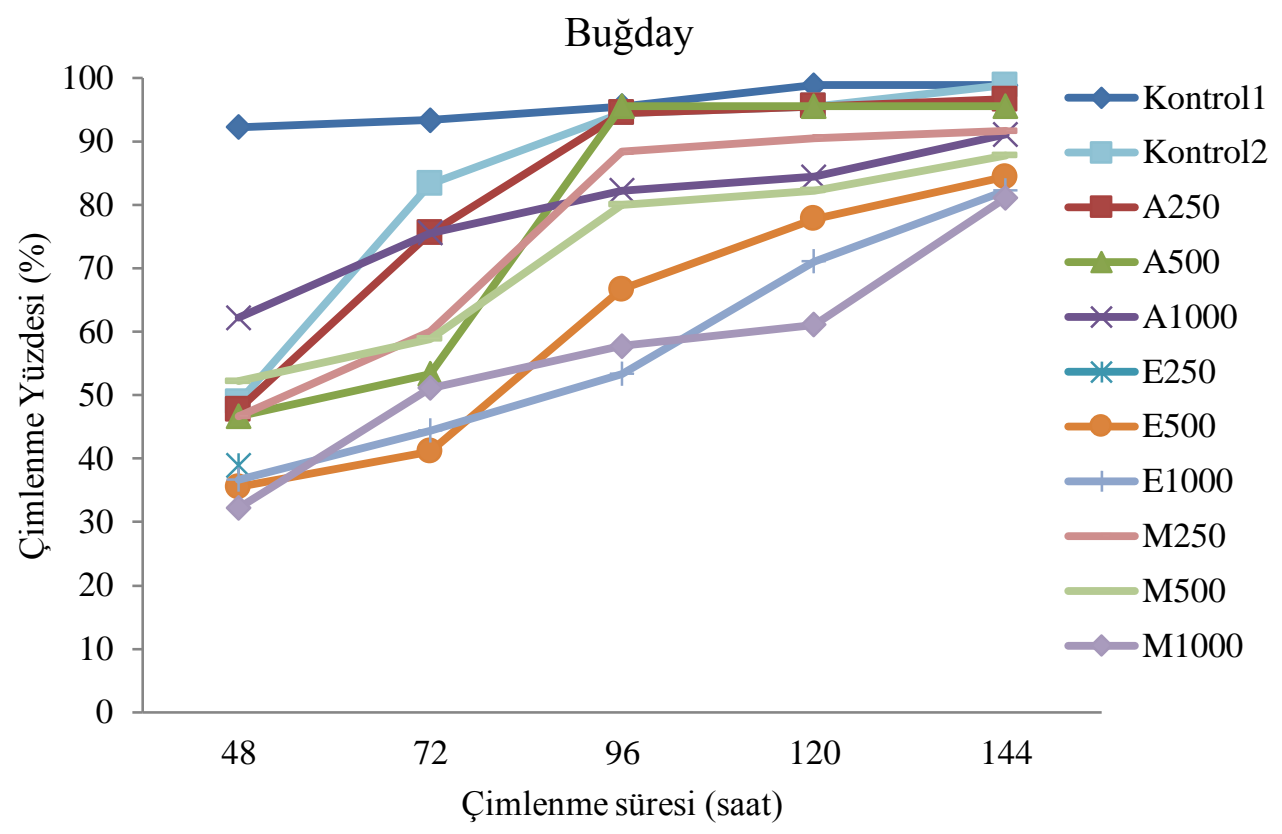

Şekil 1. Farklı çözücü ve konsantrasyonundaki biberiye ekstraktlarının buğday çimlenmesi üzerine etkisi

Şekil 1'de görüldüğü gibi ekstraktların artan konsantrasyonlarının buğday çimlenmesi üzerindeki olumsuz etkisinin olduğu, fakat bu etkinin az olduğu gözlenmiştir. Ayrıca, 144 saatin sonunda, tüm uygulamalar incelendiğinde en düşük çimlenme oranının \% 80'in üzerinde olduğu tespit edilmiştir. 72 saat sonunda, etanol ekstraktları hariç diğer ekstrakt uygulamalarinda \%50'den fazla çimlenme saptanmıştır. 96 saat sonunda, A500 ekstraktı \%95.6 ile maksimum çimlenme oranına ulaşmış ve Kontrol 1 ile aynı olduğu gözlenmiştir. 144 saat sonunda, en yüksek çimlenme \%98.9 ile Kontrol 1 ve Kontrol 2'de gözlenmiş olup, Kontrol 1, Kontrol 2, A 250 (\%96.7) ve $\mathrm{A}_{500}$ (\%95.6) arasında istatistiksel olarak anlamlı bir fark gözlenmemiştir $(p<0.05)$ (Çizelge 2). En düşük çimlenme ise \% 81.1 ile $\mathrm{M}_{1000}$ 'den elde edilmiştir. İstatiksel olarak değerlendirildiğinde etanol ve metanol ekstraktlarının tümü ile $\mathrm{A}_{1000}$ aseton ekstraktının çimlenme üzerinde olumsuz etki yaptığ ve bu farkın istatiksel olarak anlamlı olduğu kaydedilmiştir $(p<0.05)$.

Biberiye ekstraktlarının farklı konsantrasyonlardaki uygulamalarının bitki çimlenmesi üzerine etkilerinin yanı sıra bitki ağırlığı ile radikula ve plumula büyümesini önlediği de tespit edilmiştir. Uygulamalar sonucu elde edilen bitki ağırlı̆̆ının 73 ile $92 \mathrm{mg}$ arasında değiştiği ve $\mathrm{A}_{250}$ ekstrakt uygulaması $(85 \mathrm{mg}$ ) ile Kontrol 1 (92 mg) uygulaması arasında istatistiki bir fark olmadığ belirlenmiştir $(p<0.05)$. Ekstraktlar arasından $\mathrm{A}_{250}$ ekstraktı yüksek çimlenme sergilediği gibi bitki ağırlı̆̆ açısından da diğer ekstraktlara oranla daha az negatif etki sergilemesine rağmen, istatiksel olarak sadece $\mathrm{E}_{1000}$ ile farklı olduğu tespit edilmiştir.. Ayrıca tüm ekstraktların artan dozları bitki ağırlığında azalmaya neden olmuştur. Aseton çözücüsü bitki ağırlığı üzerinde etanol ve metanole göre daha az inhibitör etki göstermesine karşın bu farklılık istatistiksel açıdan önemli çıkmamıştır.

Çizelge 2. Biberiye ekstraktlarının buğdayın çimlenme ve fide büyümesi üzerine etkileri

\begin{tabular}{lllll}
\hline Ekstraktlar & Çimlenme yüzdesi $\left.{ }^{1} \%\right)$ & Radikula uzunluğu (cm) & Plumula uzunluğu (cm) & Bitki taze ağırlığı (mg) \\
\hline Kontrol1 & $98.9 \pm 0.16 \mathrm{a}$ & $5.28 \pm 0.35 \mathrm{a}$ & $4.01 \pm 0.66 \mathrm{a}$ & $92 \pm 0.6 \mathrm{a}$ \\
Kontrol2 & $98.9 \pm 0.16 \mathrm{a}$ & $1.85 \pm 0.30 \mathrm{~cd}$ & $1.94 \pm 0.08 \mathrm{cde}$ & $62 \pm 0.4 \mathrm{~d}$ \\
$\mathrm{~A}_{250}$ & $96.7 \pm 0.20 \mathrm{ab}$ & $2.03 \pm 0.46 \mathrm{~cd}$ & $1.85 \pm 0.27 \mathrm{de}$ & $85 \pm 0.6 \mathrm{ab}$ \\
$\mathrm{A}_{500}$ & $95.6 \pm 0.07 \mathrm{abc}$ & $1.22 \pm 0.11 \mathrm{~d}$ & $1.18 \pm 0.26 \mathrm{de}$ & $82 \pm 0.8 \mathrm{bc}$ \\
$\mathrm{A}_{1000}$ & $91.1 \pm 0.15 \mathrm{bcd}$ & $2.54 \pm 0.84 \mathrm{c}$ & $2.83 \pm 0.58 \mathrm{bc}$ & $80 \pm 0.5 \mathrm{bc}$ \\
$\mathrm{E}_{250}$ & $91.1 \pm 0.15 \mathrm{bcd}$ & $1.56 \pm 0.50 \mathrm{~cd}$ & $1.51 \pm 0.39 \mathrm{de}$ & $81 \pm 0.9 \mathrm{bc}$ \\
$\mathrm{E}_{500}$ & $84.4 \pm 0.14 \mathrm{~d}$ & $1.35 \pm 0.30 \mathrm{~d}$ & $1.17 \pm 0.40 \mathrm{de}$ & $80 \pm 0.9 \mathrm{bc}$ \\
$\mathrm{E}_{1000}$ & $82.2 \pm 0.10 \mathrm{~d}$ & $1.20 \pm 0.09 \mathrm{~d}$ & $1.01 \pm 0.06 \mathrm{e}$ & $73 \pm 0.2 \mathrm{c}$ \\
$\mathrm{M}_{250}$ & $91.7 \pm 0.16 \mathrm{bcd}$ & $3.56 \pm 0.00 \mathrm{~b}$ & $2.98 \pm 0.00 \mathrm{~b}$ & $77 \pm 0.0 \mathrm{bc}$ \\
$\mathrm{M}_{500}$ & $87.8 \pm 0.21 \mathrm{~cd}$ & $2.13 \pm 1.05 \mathrm{~cd}$ & $2.13 \pm 1.03 \mathrm{bcd}$ & $74 \pm 0.2 \mathrm{bc}$ \\
$\mathrm{M}_{1000}$ & $81.1 \pm 0.07 \mathrm{~d}$ & $1.83 \pm 0.85 \mathrm{~cd}$ & $1.77 \pm 0.82 \mathrm{de}$ & $75 \pm 0.5 \mathrm{bc}$ \\
\hline
\end{tabular}

${ }^{1}$ Buğday tohumlarının 144 saat sonundaki çimlenme yüzdeleri 
Aseton ekstraktları buğday tohumlarının çimlenme yüzdesi ve bitki ağırlığı üzerinde düşük etki gösterirken, radikula ve plumula uzunluğu üzerinde yüksek inhibitör etki gösterdiği belirlenmiştir. Fakat bunun aksine, $\mathrm{M}_{250}$ ekstraktları plumula ve radikula uzunlukları üzerinde diğer çözücü ektraklarına göre daha düşük inhibitör etki göstermiştir. Çözücü ekstraktlarının artan konsantrasyonları ile (aseton uygulaması hariç) inhibitör etkinin arttığı tespit edilmiştir. Benzer olarak, Hassannejad ve Garbi (2013) biberiye sulu ekstraktlarının artan konsantrasyonlarının küsküt otu tohumlarının çimlenmesi üzerine daha düşük inhibitör etki (en az \% 60 çimlenme) gösterdiği, ayrıca çimlenen tohumların taze ve kuru bitki ağırlığı üzerine etkisinin hiç yok denecek kadar az olduğunu bildirmişlerdir. Fakat biberiye uçucu yağının artan konsantrasyonlarının kültür buğday çeşitlerinin çimlenmeleri, bitki taze ağırlığı ile sürgün ve kök uzunlu üzerine kuvvetli inhibitör etki sergilediği tespit edilmiştir (Atak ve ark., 2016). Begum ve ark. (2017) tarafindan Thuja orientalis L. ve Thevetia peruviana (Pers.) Schum türlerinin metanol ekstraktlarmın artan konsantrasyonlarının buğday tohumlarının çimlenmesi, kök ve sürgün gelişimi üzerinde negatif etki yaptığı bildirilmiştir.

\section{Biberiye ekstraktlarını $S$. oryzae ve $R$. dominica erginlerine karşı kontak etkisi}

Yapılan çalışmada biberiye bitkisinin farklı çözücülerle hazırlanan ekstaraktlarının $S$. oryzae ve $R$. dominica erginleri üzerindeki kontakt toksisitesi test edilmiştir. Çalışma sonucunda 24 saatte $S$. oryzae'ye karşı en yüksek toksisiteyi \%16.67 ölüm oranı ile etanol ekstraktı uygulamasında belirlenmiştir. 48 saat (\%30) ve 72 (\%58.33) saat sonunda en yüksek ölüm oranını yine etanol ekstraktı göstermiştir (Çizelge 3). 72 saat sonunda etanol ekstraktından sonra en yüksek toksisiteyi \%33.3 ölüm oranı ile metanol ekstraktı göstermiştir (Çizelge 3). Elde edilen sonuçlar değerlendirildiğinde yetmiş 72 sonunda etanol ekstraktının etkinliği istatistiksel olarak kontrolden ve diğer muamelelerden farklı bulunmuştur $(p<0.05)$.

Biberiye bitkisinden elde edilen ekstraktlarm $R$. domincaya karşı test edilmesi sonucunda ise ilk 24 saatte en yüksek ölüm oranı \%46.67 ile aseton ekstraktında gözlemlenirken en düşük ölüm oranı ise \%33.33 ölüm oranı ile metanol ekstraktında gözlemlenmiştir (Çizelge 4). Çalışmanın 72. saatinde ise en yüksek ölüm sirasıyla aseton (\%68.33) ve etanol (\%45.00) ekstraktlarında gözlemlenmiştir. 72 saat sonunda tüm muameleler istatistiki olarak karşılaştırıldığında aseton ekstraktının kontrolden ve diğer muamelelerden farklı olduğu, metanol ve etanol ekstraktının ise istatistiki olarak aynı grupta yer aldığı, aseton ve kontrolden ise farklı olduğu bulunmuştur $(p<0.05)$.

Yapılan çalışmalarda daha çok biberiye bitkisinden elde edilen uçucu yağın zararlılar üzerindeki etkinliği test edilmiştir. Bitkiden elde edilen ekstraktların bu iki zararlı üzerindeki etkinliğini araştıran çalışmaların kısıtlı olduğu görülmektedir.

Çizelge 3. Farklı çözücülerden elde edilen biberiye ekstraktlarının Sitophilus oryzae üzerindeki kontak etkisi

\begin{tabular}{llll}
\hline \multirow{2}{*}{ Örneklers } & \multicolumn{3}{c}{ \% ölüm oranı \pm S.hata } \\
\cline { 2 - 4 } & \multicolumn{1}{c}{24 saat } & \multicolumn{1}{c}{48 saat } & 72 saat \\
\hline Kontrol & $0 \mathrm{~b}$ & $5.00 \pm 4.12 \mathrm{~b}$ & $9.17 \pm 3.29 \mathrm{c}$ \\
Metanol & $8.33 \pm 5.47 \mathrm{ab}$ & $23.33 \pm 3.49 \mathrm{a}$ & $33.33 \pm 2.09 \mathrm{~b}$ \\
Aseton & $13.33 \pm 5.84 \mathrm{a}$ & $18.33 \pm 4.86 \mathrm{a}$ & $26.67 \pm 2.46 \mathrm{~b}$ \\
Etanol & $16.67 \pm 6.80 \mathrm{a}$ & $30.00 \pm 2.57 \mathrm{a}$ & $58.33 \pm 1.80 \mathrm{a}$ \\
\hline
\end{tabular}

Aynı sütundaki ortalamaları takip eden farklı küçük harfler, ortalamaların istatistiksel olarak önemli derecede farklı olduğunu gösterir (Anova $P<0.05$, Duncan test)

Çizelge 4. Farklı çözücülerden elde edilen biberiye ekstraktlarmı Rhyzopertha dominica üzerindeki kontak etkisi

\begin{tabular}{|c|c|c|c|}
\hline \multirow{2}{*}{ Örnekler } & \multicolumn{3}{|c|}{$\%$ ölüm oranı \pm S.hata } \\
\hline & 24 saat & 48 saat & 72 saat \\
\hline Kontrol & $0 \mathrm{c}$ & $0 \mathrm{c}$ & $3.33 \pm 3.88 \mathrm{c}$ \\
\hline Metanol & $33.33 \pm 3.41 b$ & $35.00 \pm 3.02 \mathrm{~b}$ & $43.33 \pm 3.25 b$ \\
\hline Aseton & $46.67 \pm 2.88 \mathrm{a}$ & $55.00 \pm 4.57 \mathrm{a}$ & $68.33 \pm 3.62 \mathrm{a}$ \\
\hline Etanol & $26.67 \pm 2.13 \mathrm{~b}$ & $38.33 \pm 1.00 \mathrm{~b}$ & $45.00 \pm 1.97 \mathrm{~b}$ \\
\hline
\end{tabular}

Aynı sütundaki ortalamaları takip eden farklı küçük harfler, ortalamaların istatistiksel olarak önemli derecede farklı olduğunu gösterir (Anova $P<0.05$, Duncan test)

Farklı araştırıcılar tarafından yapılan çalışmalar ile $R$. officinalis in birçok zararlı böcek üzerinde farklı şekillerde etkili olduğu ortaya konulmuştur (Isikber ve ark., 2006; Saeidi ve ark. 2013; Salman ve ark., 2014; Shalaby ve Khater, 2005). Yıldırım ve ark. (2011) elde ettikleri biberiye uçucu yağının Sitohilus granarius L.üzerinde \%93 oranında ölüme neden olduğunu belirtmiştir. Biberiye uçucu yağının $S$. oryzae üzerinde test eden Kiran ve Prakash (2015) uçucu yağın 72 saat sonunda \%75 oranında ölüme sebep olduğunu tespit etmiştir. Bunun sebebinin biberiye uçucu yağlarında yüksek miktarda 1,8 cineole, $\alpha$-pinene ve $B^{-}$ caryophyllene bulunmasindan (Bertoli ve ark., 2011; Rojht ve ark., 2012; Kiran ve Prakash, 2015) kaynaklanmaktadır. Rozman ve ark. (2007) biberiye uçucu yağ bileşeni olan 1,8 cineole'nin $R$. dominica ve $S$. oryzae üzerine fumigant etkinliğini test etmişler ve $S$. oryzae üzerinde $\% 100, R$. dominica üzerinde ise $\% 97$ oranında ölüme neden olduğunu bildirmişlerdir.

Biberiye ekstraktları uçucu yağ ve uçucu yağın birleşikleri kadar depo zararlıları üzerinde etkili olmasada, Piper nigrum, Schizonepeta tenuifolia, Artemisia princeps var. orientalis gibi birçok bitki ektraklarına göre daha etkili olduğu tespit edilmiştir (Kim ve ark., 2003; Manzoor ve ark., 2011; Lucie ve ark., 2013). 


\section{SONUÇ}

Yapılan çalışmada biberiye bitkisinden farklı çözücüler kullanılarak elde edilen ekstraktların $R$. dominica ve $S$. oryzae üzerinde kullanılma potansiyeli olduğu görülmüştür. Özellikle aseton ekstraktının $R$. dominica üzerinde etkili olması ve diğer ekstraktlara göre buğday tohumları üzerinde daha az negatif etki sergilemesi (düşük dozlarda) kullanılabilirlik açısından değerlendirilebilir. İleride biberiye ekstraktlarının tahılların kalitesi üzerindeki etkileri hakkında yapılacak daha detaylı çalışmalar bu zararlılarla mücadelede kullanılabilirliğini daha net ortaya çıkartabilir.

\section{TEŞEKKÜR}

Calışmalar esnasında yardımlarından dolayı Bozok Üniversitesi Bitki Koruma Bölümü öğrencisi Osman KELEŞ'e teşekkür ederiz.

\section{KAYNAKÇA}

Ablat N, Lv D, Ren R, Xiaokaiti Y, Ma X, Zhao X, Sun Y, Lei H, Xu J, Ma Y, Qi X, Ye M, Xu F, Han H, Pu $X$ 2016. Neuroprotective effects of a standardized flavonoid extract from safflower against a rotenoneinduced rat model of Parkinson's Disease. Molecules, 21(9): E1107.

Alipour M, Saharkhiz J 2016. Phytotoxic activity and variation in essential oil content and M composition of Rosemary (Rosmarinus officinalis L.) during different phenological growth stages. Biocatalysis and Agricultural Biotechnology, 7: 271-278.

Amaral GP, Mizdal CR, Stefanello ST, Mendez ASL, Puntel RL, Campos MMA, Soares FAA, Fachinetto $\mathrm{R}$ 2018. Antibacterial and antioxidant effects of Rosmarinus officinalis L. extract and its fractions. Journal of Traditional and Complementary Medicine, 9(4): 383-392.

Aslam M, Khan KA, Bajwa MZH 2002. Potency of some spices against Callosobruchus chinensis L. OnLine Journal of Biological Sciences, 2(7): 449-452.

Atak M, Mavi K, Üremiş I 2016. Bio-Herbicidal Effects of Oregano and Rosemary Essential Oils on Germination and Seedling Growth of Bread Wheat Cultivars and Weeds. Romanian Biotechnological Letters, 21(1): 11149- 11159.

Begum P, Khan AM, Ullah I, Ahmad N 2017. Phytotoxic effects of Thuja orientalis L. and Thevetia peruviana (Pers.) Schum crude extracts on wheat seed germination. Pure and Applied Biology, 6(3): 805-813.

Bertoli A, Conti B, Mazzoni V, Meini L, Pistelli L 2012. Volatile chemical composition and bioactivity of six essential oils against the stored food insect Sitophilus zeamais Motsch. (Coleoptera Dryophthoridae). Natural Product Research, 26(22): 2063-2071.

Chen Z, Guo S, Cao J, Pang X, Geng Z, Wang Y, Zhang
Z, Du S 2018. Insecticidal and repellent activity of essential oil from Amomum villosum Lour. and its main compounds against two stored-product insects. International Journal of Food Properties, 21(1): 2265-2275.

Dikshit A, Singh AK, Tripathi RD, Dixi SN 1979. Fungitoxic and phytotoxic studies of some essential oil. Biological Bulletin of India 1: 45-51

Düzgüneş O, Kesici T, Gürbüz F 1983. İstatistik Metotları 1. Ankara Üniversitesi Ziraat Fakültesi, No: 862, Ankara.

FAO 2009. http://www.fao.org/faostat/en/\#data/QC. 28.03.2019

Gökçe A, Stelinski LL, Whalon ME, Gut L 2010. Toxicity and antifeedant activity of selected plant extracts against larval obliquebanded leafroller, Choristoneura rosaceana (Harris). The Open Entomology Journal, 4 (1): 18-24.

Guru-Pirasanna-Pandi G, Adak T, Gowda B, Patil N, Annamalai M, Jena M 2018. Toxicological effect of underutilized plant, Cleistanthus collinus leaf extracts against two major stored grain pests, the rice weevil, Sitophilus oryzae and red flour beetle, Tribolium castaneum. Ecotoxicology and Environmental Safety, 154: 92-99.

Hardman JM 1978. A logistic model simulating environmental changes associated with the growth of populations of rice weevils, Sitophilus oryzae, reared in small cells of wheat. Journal of Applied Ecology, 15: 65-87.

Hassannejad S, Ghafarbi SP 2013. Allelopathic effects of some Lamiaceae on seed germination and seedling growth of dodder (Cuscuta campestris Yunck.). International Journal of Biosciences, 3(3): 9-14.

Isikber AA, Alma MH, Kanat M, Karci A 2006. Fumigant toxicity of essential oils from Laurus nobilis and Rosmarinus officinalis against all life stages of Tribolium confusum. Phytoparasitica, 34(2): 167. https://doi.org/10.1007/BF02981317

Isman MB, Wilson JA, Bradbury R 2008. Insecticidal activities of commercial rosemary oils (Rosmarinus officinalis.) against larvae of Pseudaletia unipuncta. And Trichoplusia ni. in relation to their chemical compositions. Pharmaceutical Biology, 46 (1-2): 82-87.

Ito E, Ukpohwo R, Okiriguo I 2018. Insecticidal activity of Xylopia aethiopica (Family; Annonaceae) against Callosobruchus maculatus (F) (Coleoptera: Bruchidae) and Sitophilus oryzae (Coleoptera: Curculionidae). Journal of Biological Studies, 1(3): 106-115.

Keikhaie KR, Fazeli-Nasab B, Jahantigh HR, Hassanshahian M 2018. Antibacterial Activity of Ethyl Acetate and Methanol Extracts of Securigera securidaca, Withania sominefra, Rosmarinus officinalis and Aloe vera Plants against Important Human Pathogens. Journal of Medical 
Bacteriology, 7(1-2):13-21.

Khan SA, Ranjha MH, Khan AA, Sagheer M, Abbas A, Hassan Z 2019. Insecticidal Efficacy of Wild Medicinal Plants, Dhatura alba and Calotropis procera, against Trogoderma granarium (Everts) in Wheat Store Grains. Pakistan Journal of Zoology, 51 (1):289-294.

Kiran S, Prakash B.2015. Toxicity and biochemical efficacy of chemically characterized Rosmarinus officinalis essential oil against Sitophilus oryzae and Oryzaephilus surinamensis. Industrial Crops and Products, 74: 817-823. https://doi.org/ 10.1016/ j.indcrop.2015.05.073.

Kim S, Roh J, Kim D, Lee H, Ahn Y 2003. Insecticidal activities of aromatic plant extracts and essential oils against Sitophilus oryzae and Callosobruchus chinensis. Journal of Stored Products Research, 39 (3): 293-303.

Ksouri S, Djebir S, Bentorki AA, Gouri A, Hadef Y, Benakhla A 2017. Antifungal activity of essential oils extract from Origanum floribundum Munby, Rosmarinus officinalis L. and Thymus ciliatus Desf. against Candida albicans isolated from bovine clinical mastitis. Journal de Mycologie Médicale, 27 (2): 245-249.

Kumar D, Kalita P 2017. Reducing postharvest losses during storage of grain crops to strengthen food security in developing countries. Foods, 6(1): 8.

Lu CL, Li YM, Fu GQ, Yang L, Jiang JG, Zhu L, Lin FL, Chen J, Lin QS 2011. Extraction optimisation of daphnoretin from root bark of Wikstroemia indica (L.) C.A. and its anti-tumour activity tests. Food Chemistry 124: 1500-1506. https://doi.org/ 10.1016/ j.foodchem.2010.08.002.

Lucie AT, Dogo S, Béranger LDP, Florent BOS, Talla GM, Anna T, Salomon N, Kandioura N, Mbacké S, Jean-Laurent S 2013. Chemical Characterization and Insecticidal Activity of Ethyl Acetate and Dichloromethane Extracts of Drypetes gossweileri against Sitophilus zeamais, Tribolium castaneum and Rhyzopertha dominica. Journal of Life Sciences, 7(10): 1030-1040.

Mahdian SHA, Rahman MK 2008. Insecticidal effect of some spices on Callosobruchus maculatus (Fabricius) in black gram seeds, University Journal of Zoology Rajshahi University, 27: 47-50.

Manzoor F, Nasim G, Saif S, Malık SA 2011. Effect of ethanolic plant extracts on three storage grain pests of economic importance. Pakistan Journal of Botany, 43(6): 2941-2946.

Papachristos DP, Karamanoli KI, Stamopoulos DC, Menkissoglu-Spiroudi U 2004. The relationship between the chemical composition of three essential oils and their insecticidal activity against Acanthoscelides obtectus (Say). Pest Management Science, 60 (5): 514-520.

Pavela R 2006. Insecticidal Activity of Essential Oils Against Cabbage Aphid Brevicoryne brassicae.
Journal of Essential Oil Bearing Plants, 9 (2): 99106.

Prasad KN, Kong KW, Ramanan RN, Azlan A, Ismail A 2012. Determination and Optimization of Flavonoid and Extract Yield from Brown Mango using Response Surface Methodology. Separation Science and Technology 47: 73-80.

Rajendran P, Nandakumar N, Rengarajan T, Palaniswami R, Gnanadhas EN, Lakshminarasaiah U, Gopas J,Nishigaki I 2014. Antioxidants and human diseases. Clinica Chimica Acta, 436: 332-347.

Rajendran S 2002. Postharvest pest losses. D. Pimentel (Ed.), Encyclopedia of Pest Management, Marcel Dekker, Inc, New York, p.654-656.

Rodríguez-Rojo S, Visentin A, Maestri D, Cocero MJ 2012. Assisted extraction of rosemary antioxidants with green solvents. Journal of Food Engineering, 109 (1): 98-103.

Rojht H, Košir IJ, Trdan S 2012. Chemical analysis of three herbal extracts and observation of their activity against adults of Acanthoscelides obtectus and Leptinotarsa decemlineata using a video tracking system. Journal of Plant Diseases and Protection, 119(2):59-67. https://doi.org/10.1007/ BF03356421

Rozman V, Kalinovic I, Korunic Z 2007. Toxicity of naturally occurring compounds of Lamiaceae and Lauraceae to three stored-product insects. Journal of Stored Products Research, 43(4): 349-355. https://doi.org/10.1016/j.jspr.2006.09.001

Saeidi M, Moharramipour S 2013. Insecticidal and repellent activities of Artemisia khorassanica, Rosmarinus officinalis and Mentha longifolia essential oils on Tribolium confusum. Journal of Crop Protection, 2(1): 23-31.

Salem SA, Abou-Ela RG, Matter MM El-Kholy MY 2007. Entomocidal effect of Brassica napus extracts on two stored pests, Sitophilus oryzae (L.) and Rhyzopertha dominica (Fab.) (Coleoptera). Journal of Applied Sciences Research, 3(4): 317-322.

Salman S, Saritaş S, Kara N, AY R 2014. Acaricidal and Ovicidal Effects of Sage (Salvia officinalis L.) and Rosemary (Rosmarinus officinalis L.) (Lamiaceae) Extracts on Tetranychus urticae Koch (Acari: Tetranychidae) Tarım Bilimleri Dergisi, 20: 358-367

Sánchez-Camargo AP, Valdés A, Sullini G, GarcíaCañas V, Cifuentes A, Ibáñez E, Herrero M. 2014. Two-step sequential supercritical fluid extracts from rosemary with enhanced anti-proliferative activity. Journal of Functional Foods, 11: 293-303.

Sepehri Z, Javadian F, Khammari D, Hassanshahian M 2016. Antifungal effects of the aqueous and ethanolic leaf extracts of Echinophora platyloba and Rosmarinus officinalis. Curr Med Mycol., 2(1): $30-35$. 
Shalaby AA, Khater HF 2005. Toxicity of certain solvent extracts of Rosmarinus officinalis against Culex pipiens larvae. Journal of Egyptian- German Society of Zoology, (48E): 69- 80.

Snedecor GW, Cochran WG 1967. Statistical Methods. The Iowa State University.

Sodaeizadeh H, Rafieiolhossaini MV, Damme P 2010. Herbicidal activity of a medicinal plant, Peganum harmala L., and decomposition dynamics of its phytotoxins in the soil. Industrial Crops and Products, 31: 385-394

Tavassoli S, Mousavi SM, Emam-Djomeh Z, Razavi SH 2011. Comparative Study of the Antimicrobial Activity of Rosmarinus officinalis L. Essential Oil and Methanolic Extract. Middle-East Journal of Scientific Research, 9 (4): 467-471.

Trivedi A, Nayak N, Kumar J 2018. Recent advances and review on use of botanicals from medicinal and aromatic plants in stored grain pest management.
Journal of Entomology and Zoology Studies, 6(3): 295-300.

Vicente G, Molina S, González-Vallinas M, GarcíaRisco MR, Fornari T, Reglero G, Molina AR 2013. Supercritical rosemary extracts, their antioxidant activity and effect on hepatic tumor progression. The Journal of Supercritical Fluids, 79: 101-108.

Yeddes W, Wannes WA, Hammami M, Smida M, Chebbi A, Marzouk B, Tounsi MS 2018. Effect of Environmental Conditions on the Chemical Composition and Antioxidant Activity of Essential Oils from Rosmarinus officinalis L. Growing Wild in Tunisia, Journal of Essential Oil Bearing Plants, 21:4, 972-986.

Yıldırım E, Kordalı S, Yazıcı G 2011. Insecticidal effects of essential oils of eleven plant species from Lamiaceae on Sitophilus granarius (L.) (Coleoptera: Curculionidae). Romanian Biotechnological Letters, 16(6): 6702-6709. 